\title{
Abstract \\ Treatment of Fistula in Ano with Fistula Plug: Experience of a Tertiary Care Centre in South Asia
}

\author{
Almeida I S ${ }^{1}$, Samarasekera D N ${ }^{1}$ \\ ${ }^{1}$ Department of Surgery, Faculty of Medicine, University of Colombo, Sri Lanka
}

\section{Key words: Fistula, Fistula plug, Surgisis ${ }^{\circledR}$ AFP ${ }^{\text {TM }}$, South Asia}

\section{Introduction}

Fistula in ano remains a surgical challenge. Most of the surgical procedures for this condition are associated with troublesome consequences. The use of biologic anal fistula plug (AFP) has demonstrated excellent fistula healing. Therefore, this study was done to evaluate the efficacy of the AFP in treating patients with anorectal fistulae.

Methods

A retrospective analysis was performedon data belonging to 51 patients with cryptoglandular anorectal fistulae, who underwent a surgical procedure using AFP. Patient's demographics and characteristics of the fistulae were obtained from a database, which was maintained prospectively by the University Surgical Unit of the National Hospital of Sri Lanka from January 2007 to January 2016. Success was defined as closure of the external opening and absent drainage.

Results

51 patients were treated with anal fistula plug (male: female $=37: 14$ ) with a mean age of 42 years (SD \pm 14.86 , range26-70). Ten patients who defaulted follow-up were excluded from the analysis. Therefore, 47 procedures were left to be analysed. $29(70.7 \%)$ patients healed completely while $12(29.3 \%)$ patients failed during the follow-up period of 12 months. 24(72.7\%) simple fistulae healed successfully. Recurrent plug placement had succeeded over single plug placement $(83.33 \% \mathrm{vs.}$ $68.6 \%)$. There was no statistical significance between patient's age, sex, fistula type and its primary track with fistula healing rate $(P>0.05)$.

\section{Conclusion}

Contrary to other published studies, placement of AFP was associated with much lower fistula healing rate. Most successes were seen in simple fistulae. Repeat plug placement is associated with increased success rate. Therefore, repeat plug placements may be considered in treating patients who present with a recurrence after AFP insertion. 